\title{
Red Organic Light-Emitting-Diodes based on a N- Annulated Perylene Diimide Dimer
}

\author{
Sergey V. Dayneko, ${ }^{a}$ Mohammad Rahmati, ${ }^{b}$ Majid Pahlevani, ${ }^{c}, *$ Gregory C. Welch ${ }^{a, *}$ \\ a Department of Chemistry, University of Calgary, 731Campus Place NW, Calgary, Alberta, \\ Canada T2N $1 \mathrm{~N} 4$ \\ ${ }^{\mathrm{b}}$ Genoptic LED Inc, $600072^{\text {nd }}$ Ave SE, Calgary, AB, Canada, T2C 5B1 \\ 'Department of Electrical and Computer Engineering, Queen’s University, 19 Union St., \\ Kingston, ON, Canada, K7L 3N6
}

*E-mail: majid.pahlevani@queensu.ca and gregory.welch@ucalgary.ca

\begin{abstract}
In this contribution we report on solution processed red OLEDs based upon a Nannulated perylene diimide dimer, namely $\mathrm{tPDI}_{2} \mathrm{~N}-\mathrm{EH}$, a red-light emitting molecule. OLED devices with the architecture of glass/ITO/PEDOT:PSS/EML/LiF/Ag (EML = emitting layer) were fabricated with EMLs comprised of $\mathrm{tPDI}_{2} \mathrm{~N}-\mathrm{EH}$ neat and blended with poly $(9,9$ dicotylfluorene, PFO), all solution processed from non-halogenated solvents. The photophysical and electrophysical performance of PFO:tPDI $2 \mathrm{~N}-\mathrm{EH}-$ blend films with different composition ratios were investigated. The PFO:tPDI $2 \mathrm{~N}-\mathrm{EH}$-based OLEDs with a 2:18 ratio exhibited best performance. The PFO:tPDI $2 \mathrm{~N}-\mathrm{EH}$-based OLEDs gave red electroluminescence with the emission
\end{abstract}


wavelength of $635 \mathrm{~nm}$ and the CIE (international commission on illumination) coordinates of ( $\mathrm{x}=$ $0.672, \mathrm{y}=0.321)$. OLEDs with EMLs fabricated using roll-to-roll compatible methods are also demonstrated.

KEYWARDS: organic light emitting diode, solution processing, slot-die coating, organic dyes, perylene diimide, $\mathrm{N}$-annulation

\section{Introduction}

Organic light-emitting diodes (OLEDs) have successfully been deployed in light fixtures, mobile phones, and televisions over the past few years owing to continued improvements in both performance and lifetimes ${ }^{1-5}$. OLEDs are multilayer devices with each layer having a distinct function such as charge-injection, charge-transport, and light emission. The active emissive layer (EML) dictates the colour and maximum efficiency of OLEDs. For solution processing of

electronically active layers; spin-coating ${ }^{6}$, roll-to-roll coating ${ }^{7}$ and inkjet printing ${ }^{8}$ are the most common methods used. Solution processing is more challenging than thermal evaporation due to difficulties in forming distinct layers one on top of each other without bleeding or swelling. Recently, it has been shown that solution processed OLEDs can match the performance of thermally evaporated OLEDs ${ }^{9}$. To create high-performance solution-processed OLEDs both conjugated polymers ${ }^{10}$ and small molecules ${ }^{11}$ have been used as the core component of the EML.

To date the efficiency and purity of red colour solution processed OLEDs remains behind that of other coloured OLEDs (i.e. blue, green and orange) ${ }^{12}$. This is primarily a result of low-energy fluorescence being competitive with non-radiative decay pathways ${ }^{13}$. Most highly efficient redemitting materials are organometallic in nature ${ }^{14}$ and suffer from high costs and poor 
environmental stability. The design of new metal-free organic small molecules is a viable route towards low-cost, high-performance, large area red OLEDs.

The perylene diimide (PDI) chromophore is one of the best candidates to construct new emitters for solution-processed red OLEDs owing to a pure red colour, high quantum yield photoluminescence, and high thermal and photochemical stability ${ }^{15-17}$. Furthermore, PDIs can be

rendered soluble in a range of solvents and thus are suitable for large area roll-to-roll coating ${ }^{18-20}$. PDI-based materials have found wide utility as active materials in transistors ${ }^{21,22}$, solar cells ${ }^{23,24}$ and OLEDs ${ }^{25-27}$. PDI-based OLEDs typically have pure deep red electroluminescence with the emission wavelength of $690 \mathrm{~nm}$ and CIE coordinates of $(\mathrm{x}=0.69, \mathrm{y}=0.29)^{25}$. Recently, stable red emission from a PDI-based OLED with external quantum efficiency of $4.93 \%$ was reported ${ }^{28}$.

Here, we report red OLEDs based on an emissive dimeric PDI, namely $\mathrm{PDI}_{2} \mathrm{~N}-\mathrm{EH}$. This compound is a N-annulated PDI dimer that has found utility as a non-fullerene acceptor for organic photovoltaics ${ }^{29}$. Blending $\mathrm{PPDI}_{2} \mathrm{~N}-\mathrm{EH}$ with polyfluorene based polymers and used as the EML lead to high-performance OLED devices. The optical and electrophysical properties of PFO:tPDI $2 \mathrm{~N}-$ EH blended films were studied. The best PFO:tPDI 2 N-EH blend OLEDs were compared with high-performance PFO and poly[(9,9-di-n-octylfluorenyl-2,7-diyl)-alt-(benzo[2,1,3]thiadiazol4,8-diyl)] (F8BT) blend films. Best devices were fabricated by slot-die coating, a roll-to-roll compatible method, as proof-of-concept.

\section{Results and Discussion}

\subsection{Materials Selection}

The N-annulated PDI dimer, $\mathrm{PDI}_{2} \mathrm{~N}-\mathrm{EH}$ (Figure 1a) ${ }^{29}$, can be synthesized on multi-gram scale, is semiconducting, and can be coated via roll-to-roll processes from non-halogenated solvents ${ }^{18,19}$. It has a red luminescence peak at $650 \mathrm{~nm}$ (Figure 1b) and is chemically stable as a film in light. 
Thus, this material is appropriate for use as a solution processable light emitter. The luminescent conjugated polymers PFO and poly(9,9-dioctylfluorene-alt-benzothiadiazole) (F8BT) (structures are shown in Figure 1a) were selected as a hole transporter and control emitter, respectively, since they exhibit high light stability ${ }^{30}$ and consistent performance as light emitters in OLEDs ${ }^{31-34}$. A recent report has shown that PFO:F8BT-ink formulations are suitable to be slot-die coated into a OLED structure $^{35}$. PFO:F8BT based OLEDs were fabricated as control devices. The PFO polymer is p-type with appropriate electronic energy levels to pair with the $\mathrm{F} 8 \mathrm{BT}$ or $\mathrm{PDI}{ }_{2} \mathrm{~N}-\mathrm{EH}$ to facilitate hole transport (Figure 1c). Moreover, the wavelengths of the $\mathrm{PDDI}_{2} \mathrm{~N}-\mathrm{EH}$ absorption and $\mathrm{PFO}$ luminescence overlap (Figure 1b) enabling Förster Resonance Energy Transfer (FRET) to occur from PFO to $\mathrm{PDI}_{2} \mathrm{~N}-\mathrm{EH}$. This makes the PFO:tPDI ${ }_{2} \mathrm{~N}-\mathrm{EH}$ system an excellent candidate as a OLED EML.
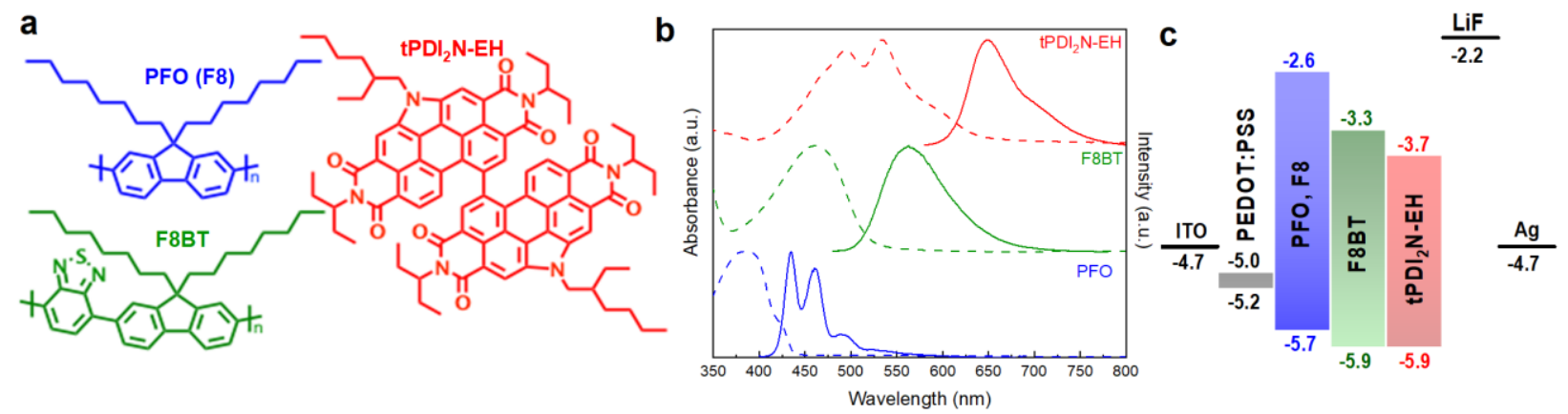

Figure 1. (a) Chemical structures of the polymers PFO (F8) and F8BT, and the small molecule $\mathrm{tPDI}_{2} \mathrm{~N}-\mathrm{EH}$ used in this study. (b) Normalized absorption and photoluminescence spectra of PFO (blue dash and solid line), F8BT (green dash and solid line), and $\mathrm{tPDI}_{2} \mathrm{~N}-\mathrm{EH}$ (red dash and solid line) films spin-cast from toluene at $15 \mathrm{mg} \mathrm{mL}^{-1}$ under $\lambda_{\mathrm{ex}}=350 \mathrm{~nm}, 400 \mathrm{~nm}$ and $530 \mathrm{~nm}$, respectively. (c) Energy level diagram with values for organic materials (energy levels taken from the relevant literature, the PEDOT:PSS has a work function of $5.0-5.2 \mathrm{eV}$ ).

\subsection{OLEDs - Spin-coated devices}




\section{Device Fabrication and Characterization}

OLED devices with the structure of glass/ITO/PEDOT:PSS/EML/LiF/Ag were fabricated and tested at ambient condition. Control devices with an EML of PFO:F8BT-blend film were spin-cast from toluene with the ratio of 19:1 at $15 \mathrm{mg} \mathrm{ml}^{-1}$. EMLs comprised of PFO:tPDI $2 \mathrm{~N}-\mathrm{EH}-\mathrm{blend}$ films were spin-cast from toluene at different ratios (from 19:1 to 1:19). The full details of the fabrication technique can be found in the electronic supplementary material (ESI). Electrical characterization of the devices was performed with a Keithley 2612B source-meter combined with the calibrated Si-photodiode and spectrometer.

\section{Photophysical properties of the PFO:tPDI 2 N-EH films}

The optical absorption and photoluminescence (PL) spectra of PFO:tPDI $2 \mathrm{~N}-\mathrm{EH}-$ blend films are shown in Figure 2. The absorption band from $330 \mathrm{~nm}$ to $430 \mathrm{~nm}$ is attributed to PFO and from 450 $\mathrm{nm}$ to $650 \mathrm{~nm}$ is attributed to $\mathrm{PDI}_{2} \mathrm{~N}-\mathrm{EH}$. Changing the ratio from 19:1 to 1:19 (PFO:tPDI ${ }_{2} \mathrm{~N}-\mathrm{EH}$ ) results in an expected decrease/increase of the $\mathrm{PFO} / \mathrm{tPDI}{ }_{2} \mathrm{~N}-\mathrm{EH}$ absorption bands with no significant changes in shape or position of each spectrum (Figure 2a).

Excitation at $400 \mathrm{~nm}$ (near peak absorption of PFO) of blended films with the ratios of 19:1 and 18:2 yields spectra with quenched emission of PFO (from 430-500 nm) and longer wave emission from $600-750 \mathrm{~nm}$ which is attributed with $\mathrm{PPDI}_{2} \mathrm{~N}-\mathrm{EH}$. The quenched PL of PFO is associated with FRET from PFO to $\mathrm{tPDI}_{2} \mathrm{~N}-\mathrm{EH}$. Increasing the concentration of $\mathrm{tPDI}_{2} \mathrm{~N}-\mathrm{EH}$ in blend films leads to complete quenching of the PFO light emission (at a ratio from 15:5 to 1:19) and increased PL of $\mathrm{PDI}_{2} \mathrm{~N}-\mathrm{EH}$ compared to neat film (Figure 2b)

Excitation at $530 \mathrm{~nm}$ of blended films results in only one emission band from $600-750 \mathrm{~nm}$, a result of PL from $\mathrm{tPDI}_{2} \mathrm{~N}-\mathrm{EH}$ (Figure 2c). When compared to PL of a neat $\mathrm{PPII}_{2} \mathrm{~N}-\mathrm{EH}$ film, there is an increase in PL intensity of $\mathrm{PDI}_{2} \mathrm{~N}-\mathrm{EH}$ films with addition of PFO. This is associated with 
exciton localization within the $\mathrm{PDI}_{2} \mathrm{~N}-\mathrm{EH}$ domains caused by the PFO energy barriers of PFO (Figure 1c). Note, the red-shift in PL spectra of $\mathrm{PPDI}_{2} \mathrm{~N}-\mathrm{EH}$ (from $630 \mathrm{~nm}$ to $650 \mathrm{~nm}$ ) with increasing $\mathrm{tPDI}_{2} \mathrm{~N}-\mathrm{EH}$ concentration is the result of aggregation of the $\mathrm{PDDI}_{2} \mathrm{~N}-\mathrm{EH}$ molecules. Thus, the PFO:tPDI 2 N-EH-blend films with ratio from 1:19 to 10:10 (highest PL intensity) appears optimum for utilization in OLEDs.
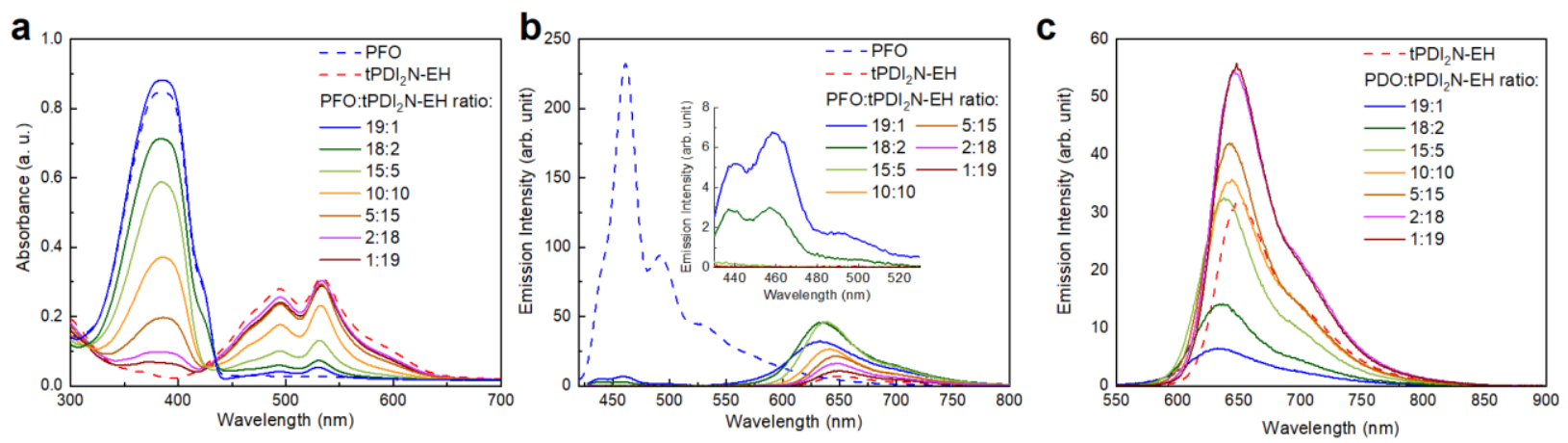

Figure 2. (a) Optical absorption and (b, c) photoluminescence spectra of PFO:tPDI 2 N-EH-blend and neat films spin-cast from toluene at $15 \mathrm{mg} \mathrm{mL}^{-1}$ under (b) $\lambda_{\mathrm{ex}}=400 \mathrm{~nm}$ and (c) $530 \mathrm{~nm}$.

Table 1. Optical properties of $\mathrm{tPDI}_{2} \mathrm{~N}-\mathrm{EH}$ and PFO:tPDI $2 \mathrm{~N}-\mathrm{EH}-\mathrm{blend}$ films.

\begin{tabular}{|c|c|c|c|c|c|}
\hline \multirow[t]{3}{*}{ Compounds } & \multirow{3}{*}{$\begin{array}{l}\mathrm{PFO}: \mathrm{PDDI}_{2} \mathrm{~N}-\mathrm{EH} \\
\text { ratio }\end{array}$} & \multicolumn{4}{|c|}{ Emission of $\mathrm{tPDI}_{2} \mathrm{~N}-\mathrm{EH}$} \\
\hline & & \multicolumn{2}{|c|}{ under $\lambda_{\mathrm{ex}}=400 \mathrm{~nm}$} & \multicolumn{2}{|c|}{ under $\lambda_{\mathrm{ex}}=530 \mathrm{~nm}$} \\
\hline & & $\max$ & FWHW $^{1}$ & $\max$ & FWHM \\
\hline PFO:tPDI ${ }_{2} \mathrm{~N}-\mathrm{EH}$ & 19:1 & 633 & 77 & 633 & 75 \\
\hline PFO:tPDI ${ }_{2} \mathrm{~N}-\mathrm{EH}$ & $18: 2$ & 635 & 63 & 636 & 62 \\
\hline PFO:tPDI ${ }_{2} \mathrm{~N}-\mathrm{EH}$ & $15: 5$ & 639 & 55 & 638 & 55 \\
\hline PFO:tPDI ${ }_{2} \mathrm{~N}-\mathrm{EH}$ & 10:10 & 641 & 57 & 642 & 57 \\
\hline PFO:tPDI ${ }_{2} \mathrm{~N}-\mathrm{EH}$ & $5: 15$ & 645 & 54 & 644 & 55 \\
\hline PFO:tPDI ${ }_{2} \mathrm{~N}-\mathrm{EH}$ & $2: 18$ & 646 & 57 & 647 & 60 \\
\hline PFO:tPDI ${ }_{2} \mathrm{~N}-\mathrm{EH}$ & $1: 19$ & 648 & 56 & 647 & 57 \\
\hline $\mathrm{tPDI}_{2} \mathrm{~N}-\mathrm{EH}^{2}$ & - & 653 & 60 & 650 & 60 \\
\hline
\end{tabular}

${ }^{1} \mathrm{FWHM}$ - full width at half maximum; $\mathrm{PPDI}_{2} \mathrm{~N}-\mathrm{EH}$ and PFO:tPDI $2 \mathrm{~N}-\mathrm{EH}-\mathrm{blend}$ films was spin-cast on glass from toluene at $15 \mathrm{mg} \mathrm{mL}^{-1}$.

${ }^{2}$ Quantum yield photoluminescence of tPDI 2 N-EH film of $16 \%$. 
OLED device characteristics based on $\mathrm{PPDI}_{2} \mathrm{~N}-\mathrm{EH}$ and PFO:tPDI ${ }_{2} \mathrm{~N}-\mathrm{EH}-$ blend films with different ratios are shown in Figure 3 and Table 2; the data include graphics of current densityvoltage curves (J-V, Figure 3a), luminance versus applied voltage curves (L-V, Figure $3 b)$ and luminous efficiency versus current density curves (LE-J, Figure 3c). The OLEDs based on only tPDI $_{2} \mathrm{~N}-\mathrm{EH}$ films as the EML showed a maximum luminous efficiency (LE) of around $4 * 10^{-3} \mathrm{~cd}$ $\mathrm{A}^{-1}$ with a maximum brightness of $4.1 \mathrm{~cd} \mathrm{~m}^{-2}$, which agree well with the previously obtained data for other PDI-based OLEDs ${ }^{25}$. The highest performance OLEDs were based on PFO:tPDI $2 \mathrm{~N}-\mathrm{EH}$ EML with the blend ratio of 2:18 and had the maximum LE of $0.05 \mathrm{~cd} \mathrm{~A}^{-1}$, power efficiency (PE) of $0.03 \mathrm{~lm} \mathrm{~W} \mathrm{~W}^{-1}$, and external quantum efficiency (EQE) of $0.06 \%$. Increasing the concentration of PFO in PFO:tPDI 2 N-EH-blend leads to performance deterioration of the fabricated OLEDs, which agrees well with the PL data (Figure S1). The turn-on voltage of the $\mathrm{PDDI}_{2} \mathrm{~N}-\mathrm{EH}$-based OLEDs decreases when PFO is added to the EML. Adding the PFO, which has a higher lying HOMO energy level than $\mathrm{PDDI}_{2} \mathrm{~N}-\mathrm{EH}$, helps facilitate hole injection from PEDOT:PSS to the EML. The turn-on voltage of $2.6 \mathrm{~V}$ for the OLEDs with PFO:tPDI 2 N-EH EMLs is the lowest reported for PDI-based OLEDs ${ }^{25,26,28,36}$.
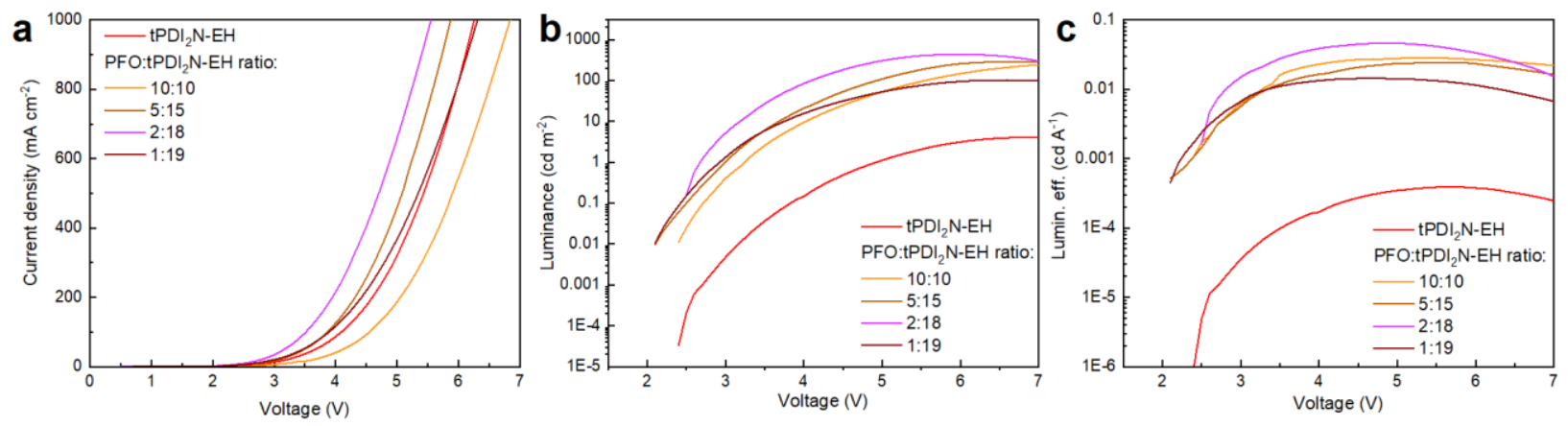

Figure 3. (a) Current density-voltage $(J-V)$ characteristics, (b) luminance versus applied voltage $\left(L-V, \mathrm{~cd} \mathrm{~m}^{-2}\right)$ and (c) luminous efficiency (lumin. eff.) versus current density $\left(L E-J, \mathrm{~cd} \mathrm{~A}^{-1}\right)$ of PFO:tPDI ${ }_{2} \mathrm{~N}-\mathrm{EH}$ OLEDs at selected ratios. 
Table 2. Summary of device performance for OLEDs based on $\mathrm{tPDI}_{2} \mathrm{~N}-\mathrm{EH}$ and PFO:tPDI ${ }_{2} \mathrm{~N}-\mathrm{EH}-$ blend films with different ratio spin-coated on the glass.

\begin{tabular}{lllllll}
\hline Emitting layer & ratio $^{1}$ & $\begin{array}{l}V_{\text {on }} \\
{[\mathrm{V}]^{2}}\end{array}$ & $\begin{array}{l}\mathrm{EQE}_{\max } \\
{[\%]^{3}}\end{array}$ & $\begin{array}{l}\mathrm{LE}_{\max } \\
{\left[\mathrm{cd} \mathrm{A}^{-1}\right]^{4}}\end{array}$ & $\begin{array}{l}\mathrm{PE}_{\max } \\
{\left[\mathrm{lm} \mathrm{W}^{-1}\right]^{5}}\end{array}$ & $\begin{array}{l}\mathrm{L}_{\max } \\
{\left[\mathrm{cd} \mathrm{m}^{-2}\right]^{6}}\end{array}$ \\
\hline tPDI $_{2} \mathrm{~N}-\mathrm{EH}$ & - & 4.9 & 0.000504 & 0.000392 & 0.000236 & 4.1 \\
PFO: tPDI $_{2} \mathrm{~N}-\mathrm{EH}$ & $10: 10$ & 3.2 & 0.035 & 0.028 & 0.019 & 262.3 \\
PFO: tPDI $_{2} \mathrm{~N}-\mathrm{EH}$ & $5: 15$ & 3.0 & 0.031 & 0.025 & 0.015 & 288.5 \\
PFO: tPDI $_{2} \mathrm{~N}-\mathrm{EH}$ & $2: 18$ & 2.6 & 0.057 & 0.046 & 0.031 & 435.4 \\
PFO: PPDI $_{2} \mathrm{~N}-\mathrm{EH}$ & $1: 19$ & 2.7 & 0.018 & 0.014 & 0.010 & 101.8 \\
\hline
\end{tabular}

${ }^{1} \mathrm{PFO}: \mathrm{tPDI}_{2} \mathrm{~N}-\mathrm{EH}$ ratio

${ }^{2}$ Turn on voltage was determined at the brightness of $1 \mathrm{~cd} \mathrm{~m}^{-2}$

${ }^{3} \mathrm{EQE}$ - external quantum efficiency

${ }^{4} \mathrm{LE}$ - luminous efficiency

${ }^{5} \mathrm{PE}$ - power efficiency

${ }^{6} L_{\max }$ - maximum of luminous

\section{OLED Electroluminescence}

The electroluminescence (EL), CIE, and current-voltage-luminance characteristics of PFO:F8BT (19:1 ratio) and optimized PFO:tPDI 2 -EH-based (2:18 ratio) OLEDs are shown in Figure 4 and Table 3. PFO:F8BT-based OLEDs demonstrated the maximum LE of $1.24 \mathrm{~cd} \mathrm{~A}^{-1}$, PE of $0.4 \mathrm{~lm} \mathrm{~W}^{-1}$ and brightness of $1950 \mathrm{~cd} \mathrm{~m}^{-2}$ with white-green spectrum at maximum of 530 $\mathrm{nm}$, full width at half maximum (FWHM) of $105 \mathrm{~nm}$, and CIE coordinates located at $(\mathrm{x}, \mathrm{y})=(0.383$, $\mathrm{y}=0.514)$. This data is well aligned with literature ${ }^{32,35}$. Using tPDI $2 \mathrm{~N}-\mathrm{EH}$ instead of F8BT with PFO shifts the EL to red, which agrees well with the PL of $\mathrm{tPDI}_{2} \mathrm{~N}-\mathrm{EH}$. The PFO:tPDI ${ }_{2} \mathrm{~N}-\mathrm{EH}-$ based OLEDs exhibit a narrow peak of EL with the maximum emission at $635 \mathrm{~nm}$ and FWHM of $60 \mathrm{~nm}$ with the CIE coordinates of $(\mathrm{x}, \mathrm{y})=(0.672,0.321)$. Moreover, using $\mathrm{PPDI}_{2} \mathrm{~N}-\mathrm{EH}$ decreases the turn-on voltage to $2.6 \mathrm{~V}$ due to the lower LUMO energy level and easy injection of electrons from the contacts to the active layer. 

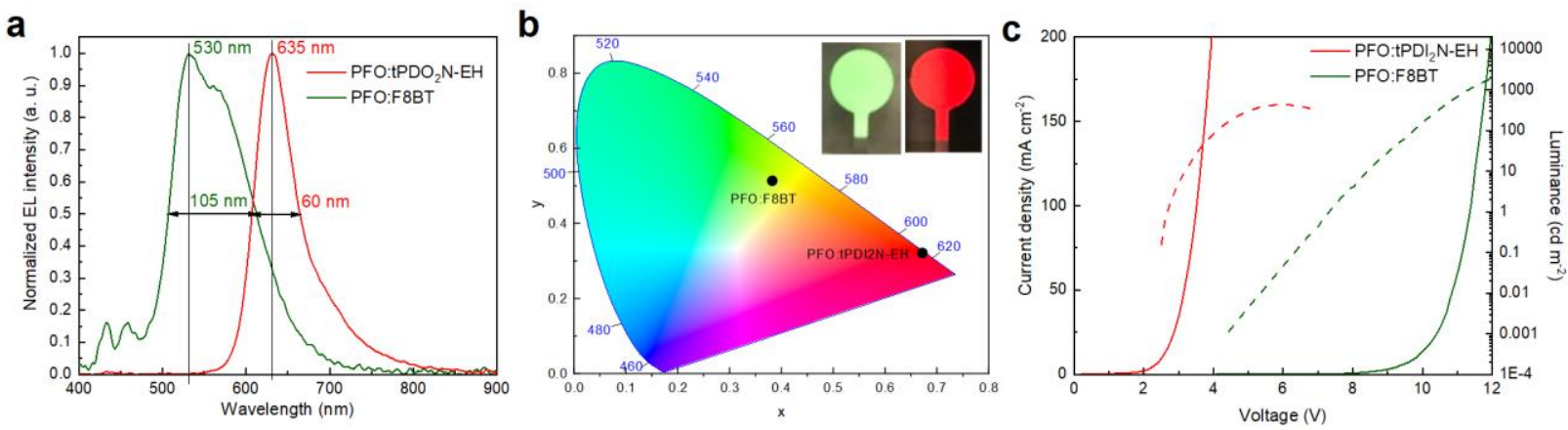

Figure 4. (a) Normalized electroluminescence (EL) and (b) color coordinates spectra, (c) currentvoltage-luminance characteristics of PFO:F8BT (ratio 19:1) and PFO:tPDI 2 N-EH (ratio 2:18) blends.

Table 3. Summary of device performance for OLEDs based on PFO:F8BT and PFO:tPDI 2 N-EHblend films spin-coated on glass.

\begin{tabular}{lllllll}
\hline Emitting layer & ratio $^{1}$ & $\begin{array}{l}V_{\text {on }} \\
{[\mathrm{V}]^{2}}\end{array}$ & $\begin{array}{l}\text { EQEmax } \\
{[\%]^{3}}\end{array}$ & $\begin{array}{l}L E_{\max } \\
{\left[\mathrm{cd} \mathrm{A}^{-1}\right]^{4}}\end{array}$ & $\begin{array}{l}P E_{\max } \\
{\left[\mathrm{lm} \mathrm{W}^{-1}\right]^{5}}\end{array}$ & $\begin{array}{l}L \max \\
{\left[\mathrm{cd} \mathrm{m}^{-2}\right]^{6}}\end{array}$ \\
\hline PFO:F8BT & $19: 1$ & 7.3 & 0.406 & 1.24 & 0.376 & 1951.6 \\
PFO:tPDI 2 N-EH & $2: 18$ & 2.6 & 0.057 & 0.046 & 0.031 & 435.4 \\
\hline${ }^{1}$ PFO:F8BT or PFO:tPDI 2 N-EH ratio & & & \\
2Turn on voltage was determined at the brightness of $1 \mathrm{~cd} \mathrm{~m}^{-2}$ & & \\
${ }^{3} \mathrm{EQE}$ - external quantum efficiency & & & \\
${ }^{4} \mathrm{LE}$ - luminous efficiency \\
${ }^{5} \mathrm{PE}$ - power efficiency \\
${ }^{6} \mathrm{Lmax}$ - maximum of luminous
\end{tabular}

\subsection{OLEDs - slot-die coated devices}

The roll-to-roll compatibility of organic and inorganic layers of OLED devices is an important consideration for large-scale fabrication methods ${ }^{7}$. Thus, we aimed to repeat our best spin-coated devices with a slot-die coating technique. A FOM Nano Roll Coater (slot-die head with $13 \mathrm{~mm}$ shim width) was used to coat both the PEDOT:PSS interlayer and PFO:tPDI $2 \mathrm{~N}-\mathrm{EH}(2: 18)$ EML onto a PET/ITO substrate/anode base. The PEDOT:PSS interlayer was slot-die coated with the 
coating speed of $0.1 \mathrm{~mm}^{-1}$, dispensing rate of $12 \mu \mathrm{L} \mathrm{min}^{-1}$, and substrate temperature of $50^{\circ} \mathrm{C}$. The layer was thermally annealed at $100{ }^{\circ} \mathrm{C}$ for 15 min prior to the deposition of the EML. The PFO:tPDI 2 N-EH (2:18) solutions were coated from toluene at $30 \mathrm{mg} \mathrm{mL}^{-1}$ with the coating speed of $0.3 \mathrm{~mm}^{-1}$, dispensing rate of $30 \mu \mathrm{L} \mathrm{min}^{-1}$ at room temperature. The films were then dried in air at $100{ }^{\circ} \mathrm{C}$ for 30 minutes. $\mathrm{A} \mathrm{LiF} / \mathrm{Ag}$ electrode was thermally deposited using a thermal evaporation system through a shadow mask under a base pressure of $\sim 2 \times 10^{-6}$ torr (this top electrode was used for consistency in comparing to the spin-coated OLEDs). The device area was $160 \mathrm{~mm}^{2}$ as defined by the overlapping area of the ITO films and top electrodes. The optical absorption spectra of the roll-to-roll coated devices (in comparison to the spin-coated ones) can be found in the ESI (Figure S2).

The current-voltage-luminance characteristics and $L E$ versus current density of OLED devices with the PEDOT:PSS and PFO:tPDI $2 \mathrm{~N}-\mathrm{EH}$ layers roll-to-roll coated on PET are shown in Figure 5 and electrophysical parameters are summarized in Table 4. The OLEDs had a turn-on voltage of 6.6 $\mathrm{V}$ and maximum brightness of $1.1 \mathrm{~cd} \mathrm{~m}^{-2}$, demonstrating a fully functioning large area, roll-toroll compatible coated device. Thus, this work shows that large-area OLEDs can be fabricated using slot-die coating techniques. The synthesis of new PDIs with high quantum yield and narrow peak luminescence of films, and optimized roll-to-roll coating of OLED layers is a viable pathway towards developing high-performance OLEDs for large-scale manufacturing.
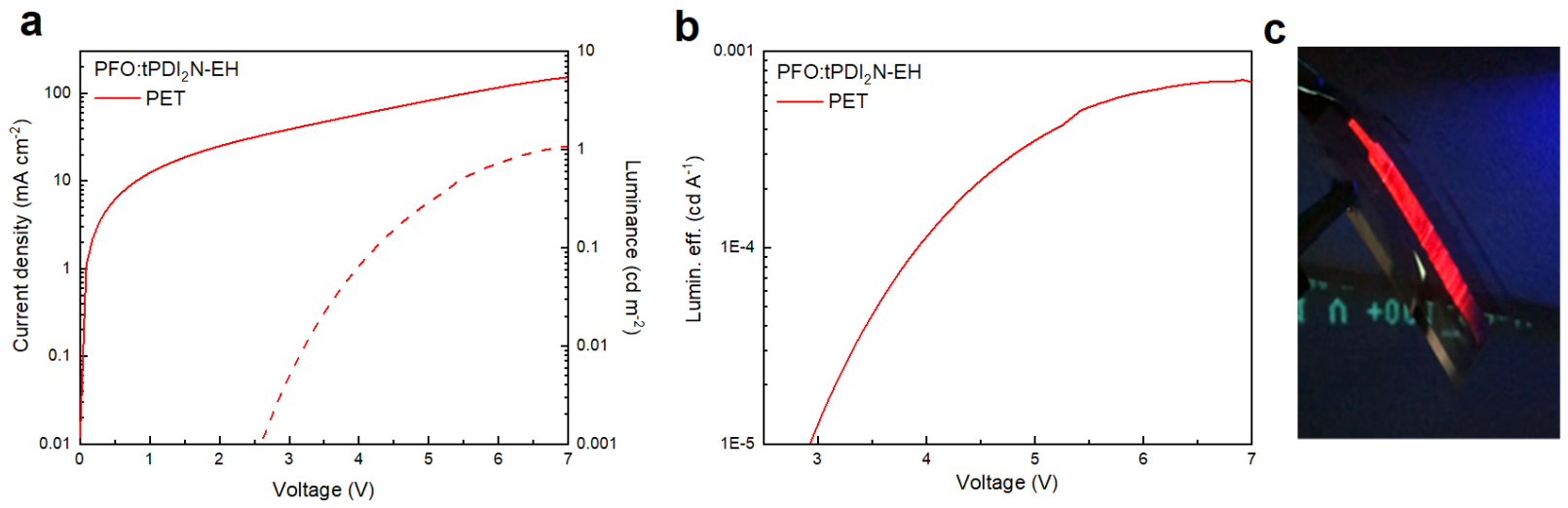
Films 5. (a) Current-voltage-luminance characteristics and (b) luminous efficiency (lumin. eff.) versus current density (LE-J, cd A ${ }^{-1}$ ) of PFO:tPDI 2 N-EH roll-to-roll coated on PET. (c) Photo of electroluminescent of PFO:tPDI 2 N-EH OLEDs on PET.

Table 4. Summary of device performance for spin-cast and slot-die coating OLEDs based on PFO:tPDI 2 N-EH-blend films.

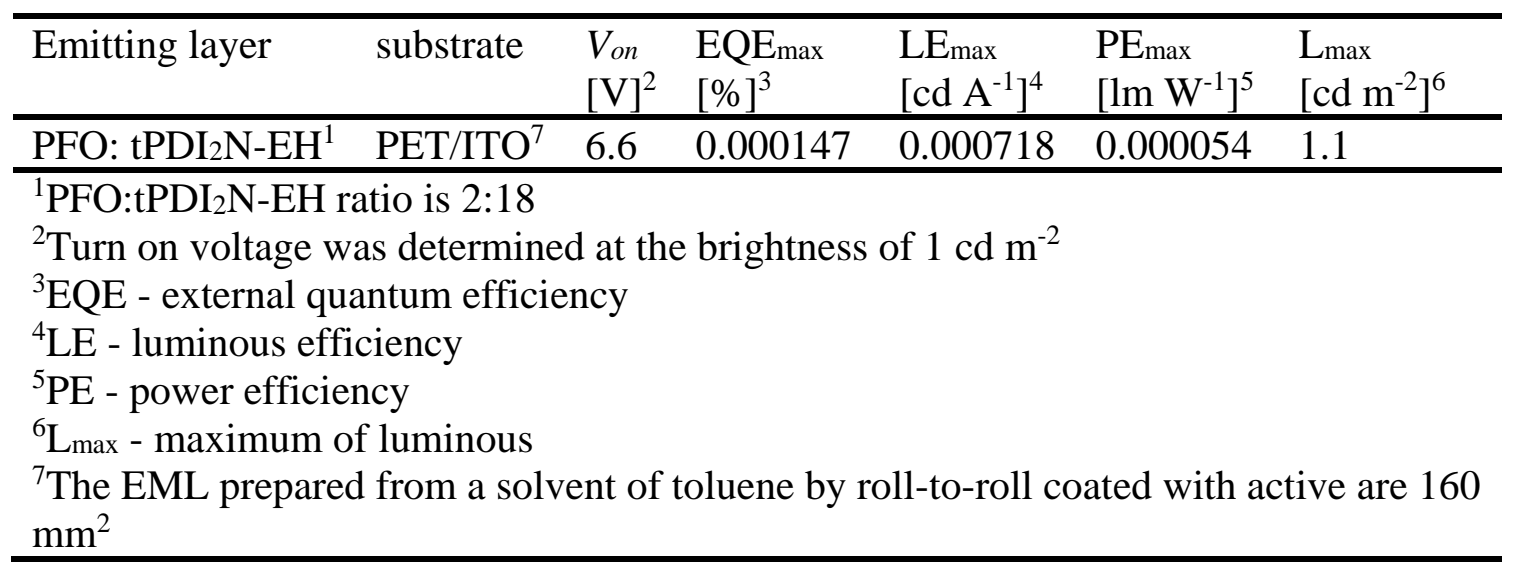

\section{Conclusion}

We have presented electrically pumped, solution processed red OLEDs based on a N-annulated perylene diimide dimer as the emitting material. Use of the polyfluorene based polymer PFO as an additive for the red-emitter $\mathrm{tPDI}_{2} \mathrm{~N}-\mathrm{EH}$ resulted in large performance boosts with an optimal PFO:tPDI 2 N-EH ratio of 2:18 identified. The best efficiencies of PFO:tPDI 2 N-EH-based OLEDs exhibited a maximum LE of $0.05 \mathrm{~cd} \mathrm{~A}^{-1}$, power efficiency (PE) of $0.031 \mathrm{~m} \mathrm{~W}^{-1}$ and external quantum efficiency (EQE) of $0.06 \%$, and are among the best for PDI-based OLEDs. Proof-ofconcept large-scale fabrication of OLEDs was demonstrated by roll-to-roll compatible coating of both the PEDOT:PSS hole injection layer and PFO:tPDI2N-EH emitting layer of OLEDs with large area $\left(160 \mathrm{~mm}^{2}\right)$ on plastic substrates. This work highlights the potential of $\mathrm{N}$-annulated perylene diimide based materials to deliver commercially relevant advanced lighting devices. 


\section{Acknowledgement}

GCW acknowledges CFI JELF (34102), CRC, WED, and the University of Calgary. SVD is grateful for a MITACS fellowship. Authors would like to thank GenOptic LED Inc. for their financial support.

\section{References}

(1) Chen, H.-W.; Lee, J.-H.; Lin, B.-Y.; Chen, S.; Wu, S.-T. Liquid Crystal Display and Organic Light-Emitting Diode Display: Present Status and Future Perspectives. Light Sci. Appl. 2018, 7 (3), 17168-17168. https://doi.org/10.1038/lsa.2017.168.

(2) Ràfols-Ribé, J.; Will, P.-A.; Hänisch, C.; Gonzalez-Silveira, M.; Lenk, S.; Rodríguez-Viejo, J.; Reineke, S. High-Performance Organic Light-Emitting Diodes Comprising Ultrastable Glass Layers. Sci. Adv. 2018, 4 (5), eaar8332. https://doi.org/10.1126/sciadv.aar8332.

(3) Kotadiya, N. B.; Blom, P. W. M.; Wetzelaer, G.-J. A. H. Efficient and Stable Single-Layer Organic Light-Emitting Diodes Based on Thermally Activated Delayed Fluorescence. Nat. Photonics 2019. https://doi.org/10.1038/s41566-019-0488-1.

(4) Guo, K.; Wang, H.; Wang, Z.; Si, C.; Peng, C.; Chen, G.; Zhang, J.; Wang, G.; Wei, B. Stable Green Phosphorescence Organic Light-Emitting Diodes with Low Efficiency Rolloff Using a Novel Bipolar Thermally Activated Delayed Fluorescence Material as Host. Chem. Sci. 2017, 8 (2), 1259-1268. https://doi.org/10.1039/C6SC03008D.

(5) Sato, S.; Ohisa, S.; Hayashi, Y.; Sato, R.; Yokoyama, D.; Kato, T.; Suzuki, M.; Chiba, T.; Pu, Y.; Kido, J. Air-Stable and High-Performance Solution-Processed Organic LightEmitting Devices Based on Hydrophobic Polymeric Ionic Liquid Carrier-Injection Layers. Adv. Mater. 2018, 30 (18), 1705915. https://doi.org/10.1002/adma.201705915. 
(6) Lee, B. R.; Jung, E. D.; Park, J. S.; Nam, Y. S.; Min, S. H.; Kim, B.-S.; Lee, K.-M.; Jeong, J.-R.; Friend, R. H.; Kim, J.-S.; et al. Highly Efficient Inverted Polymer Light-Emitting Diodes Using Surface Modifications of ZnO Layer. Nat. Commun. 2014, 5 (1), 4840. https://doi.org/10.1038/ncomms5840.

(7) Sandström, A.; Dam, H. F.; Krebs, F. C.; Edman, L. Ambient Fabrication of Flexible and Large-Area Organic Light-Emitting Devices Using Slot-Die Coating. Nat. Commun. 2012, 3 (1), 1002. https://doi.org/10.1038/ncomms2002.

(8) C, A.; Szymański, M. Z.; Łuszczyńska, B.; Ulański, J. Inkjet Printing of Super Yellow: Ink Formulation, Film Optimization, OLEDs Fabrication, and Transient Electroluminescence. Sci. Rep. 2019, 9 (1), 8493. https://doi.org/10.1038/s41598-019-44824-w.

(9) Sree, V. G.; Park, H.; Cho, W.; Jin, S.-H. High Efficient Vacuum Deposited Red Organic Light-Emitting Diodes Compared with Their Solution-Processed Counterpart. Mol. Cryst. Liq. Cryst. 2017, 654 (1), 73-82. https://doi.org/10.1080/15421406.2017.1355696.

(10) Burns, S.; MacLeod, J.; Trang Do, T.; Sonar, P.; Yambem, S. D. Effect of Thermal Annealing Super Yellow Emissive Layer on Efficiency of OLEDs. Sci. Rep. 2017, 7 (1), 40805. https://doi.org/10.1038/srep40805.

(11) Aizawa, N.; Pu, Y.-J.; Watanabe, M.; Chiba, T.; Ideta, K.; Toyota, N.; Igarashi, M.; Suzuri, Y.; Sasabe, H.; Kido, J. Solution-Processed Multilayer Small-Molecule Light-Emitting Devices with High-Efficiency White-Light Emission. Nat. Commun. 2014, 5 (1), 5756. https://doi.org/10.1038/ncomms6756.

(12) Wei, Q.; Fei, N.; Islam, A.; Lei, T.; Hong, L.; Peng, R.; Fan, X.; Chen, L.; Gao, P.; Ge, Z. 
Small-Molecule Emitters with High Quantum Efficiency: Mechanisms, Structures, and Applications in OLED Devices. Adv. Opt. Mater. 2018, 6 (20), 1800512. https://doi.org/10.1002/adom.201800512.

(13) Zhang, Q.; Kuwabara, H.; Potscavage, W. J.; Huang, S.; Hatae, Y.; Shibata, T.; Adachi, C. Anthraquinone-Based Intramolecular Charge-Transfer Compounds: Computational Molecular Design, Thermally Activated Delayed Fluorescence, and Highly Efficient Red Electroluminescence. J. Am. Chem. Soc. 2014, 136 (52), 18070-18081. https://doi.org/10.1021/ja510144h.

(14) Xiang, H.; Cheng, J.; Ma, X.; Zhou, X.; Chruma, J. J. Near-Infrared Phosphorescence: Materials and Applications. Chem. Soc. Rev. 2013, 42 (14), 6128. https://doi.org/10.1039/c3cs60029g.

(15) Schmidt, D.; Stolte, M.; Süß, J.; Liess, A.; Stepanenko, V.; Würthner, F. Protein-like Enwrapped Perylene Bisimide Chromophore as a Bright Microcrystalline Emitter Material. Angew. Chemie Int. Ed. 2019, $58 \quad$ (38), 13385-13389. https://doi.org/10.1002/anie.201907618.

(16) Sabatini, R. P.; Zhang, B.; Gupta, A.; Leoni, J.; Wong, W. W. H.; Lakhwani, G. Molecularly Isolated Perylene Diimides Enable Both Strong Exciton-Photon Coupling and High Photoluminescence Quantum Yield. J. Mater. Chem. C 2019, 7 (10), 2954-2960. https://doi.org/10.1039/C9TC00093C.

(17) Zhang, B.; Soleimaninejad, H.; Jones, D. J.; White, J. M.; Ghiggino, K. P.; Smith, T. A.; Wong, W. W. H. Highly Fluorescent Molecularly Insulated Perylene Diimides: Effect of Concentration on Photophysical Properties. Chem. Mater. 2017, 29 (19), 8395-8403. 
https://doi.org/10.1021/acs.chemmater.7b02968.

(18) Laventure, A.; Harding, C. R.; Cieplechowicz, E.; Li, Z.; Wang, J.; Zou, Y.; Welch, G. C. Screening Quinoxaline-Type Donor Polymers for Roll-to-Roll Processing Compatible Organic Photovoltaics. ACS Appl. Polym. Mater. 2019, acsapm.9b00433. https://doi.org/10.1021/acsapm.9b00433.

(19) Tintori, F.; Laventure, A.; Welch, G. C. Perylene Diimide Based Organic Photovoltaics with Slot-Die Coated Active Layers from Halogen-Free Solvents in Air at Room Temperature. ACS Appl. Mater. Interfaces 2019, acsami.9b14251. https://doi.org/10.1021/acsami.9b14251.

(20) Laventure, A.; Stanzel, S.; Payne, A.-J.; Lessard, B. H.; Welch, G. C. A Ring Fused NAnnulated PDI Non-Fullerene Acceptor for High Open Circuit Voltage Solar Cells Processed from Non-Halogenated Solvents. Synth. Met. 2019, 250, 55-62. https://doi.org/10.1016/j.synthmet.2019.02.010.

(21) Gupta, R. K.; Dey, A.; Singh, A.; Iyer, P. K.; Sudhakar, A. A. Heteroatom Bay-Annulated Perylene Bisimides: New Materials for Organic Field Effect Transistors. ACS Appl. Electron. Mater. 2019, 1 (8), 1378-1386. https://doi.org/10.1021/acsaelm.9b00004.

(22) Li, G.; Li, D.; Liu, X.; Xu, H.; Zhang, J.; Wang, S.; Liu, Z.; Tang, B. Novel Dithiano-Thieno Fused Perylene Diimides: Synthesis, Characterization and Application in Organic ThinFilm Transistors (OTFTs). Chem. Commun. 2019, 55 (65), 9661-9664. https://doi.org/10.1039/C9CC04133H.

(23) Sun, D.; Meng, D.; Cai, Y.; Fan, B.; Li, Y.; Jiang, W.; Huo, L.; Sun, Y.; Wang, Z. Non- 
Fullerene-Acceptor-Based Bulk-Heterojunction Organic Solar Cells with Efficiency over 7\%. J. Am. Chem. Soc. 2015, 137 (34), 11156-11162. https://doi.org/10.1021/jacs.5b06414.

(24) Zhang, J.; Li, Y.; Huang, J.; Hu, H.; Zhang, G.; Ma, T.; Chow, P. C. Y.; Ade, H.; Pan, D.; Yan, H. Ring-Fusion of Perylene Diimide Acceptor Enabling Efficient Nonfullerene Organic Solar Cells with a Small Voltage Loss. J. Am. Chem. Soc. 2017, 139 (45), 1609216095. https://doi.org/10.1021/jacs.7b09998.

(25) Kozma, E.; Mróz, W.; Villafiorita-Monteleone, F.; Galeotti, F.; Andicsová-Eckstein, A.; Catellani, M.; Botta, C. Perylene Diimide Derivatives as Red and Deep Red-Emitters for Fully Solution Processable OLEDs. RSC Adv. 2016, 6 (66), 61175-61179. https://doi.org/10.1039/C6RA10467C.

(26) Li, G.; Zhao, Y.; Li, J.; Cao, J.; Zhu, J.; Sun, X. W.; Zhang, Q. Synthesis, Characterization, Physical Properties, and OLED Application of Single BN-Fused Perylene Diimide. J. Org. Chem. 2015, 80 (1), 196-203. https://doi.org/10.1021/jo502296z.

(27) Matussek, M.; Filapek, M.; Gancarz, P.; Krompiec, S.; Grzegorz Małecki, J.; Kotowicz, S.; Siwy, M.; Maćkowski, S.; Chrobok, A.; Schab-Balcerzak, E.; et al. Synthesis and Photophysical Properties of New Perylene Bisimide Derivatives for Application as Emitting Materials in OLEDs. Dye. Pigment. 2018, 159, 590-599. https://doi.org/10.1016/j.dyepig.2018.07.006.

(28) Zong, L.; Gong, Y.; Yu, Y.; Xie, Y.; Xie, G.; Peng, Q.; Li, Q.; Li, Z. New Perylene Diimide Derivatives: Stable Red Emission, Adjustable Property from ACQ to AIE, and Good Device Performance with an EQE Value of 4.93\%. Sci. Bull. 2018, 63 (2), 108-116. https://doi.org/10.1016/j.scib.2017.10.021. 
Dayneko, S. V.; Hendsbee, A. D.; Welch, G. C. Combining Facile Synthetic Methods with Greener Processing for Efficient Polymer-Perylene Diimide Based Organic Solar Cells. Small Methods 2018, 2 (6), 1800081. https://doi.org/10.1002/smtd.201800081.

(30) Smirnov, J. R. C.; Sousaraei, A.; Osorio, M. R.; Casado, S.; Hernández, J. J.; Wu, L.; Zhang, Q.; Xia, R.; Granados, D.; Wannemacher, R.; et al. Flexible Distributed Feedback Lasers Based on Nanoimprinted Cellulose Diacetate with Efficient Multiple Wavelength Lasing. npj Flex. Electron. 2019, 3 (1), 17. https://doi.org/10.1038/s41528-019-0062-4.

(31) Ahn, J. H.; Wang, C.; Perepichka, I. F.; Bryce, M. R.; Petty, M. C. Blue Organic Light Emitting Devices with Improved Colour Purity and Efficiency through Blending of Poly(9,9-Dioctyl-2,7-Fluorene) with an Electron Transporting Material. J. Mater. Chem. 2007, 17 (29), 2996. https://doi.org/10.1039/b700047b.

(32) de Azevedo, D.; Freitas, J. N.; Domingues, R. A.; Faleiros, M. M.; Atvars, T. D. Z. Correlation between the PL and EL Emissions of Polyfluorene-Based Diodes Using Bilayers or Polymer Blends. Synth. Met. 2017, 233, 28-34. https://doi.org/10.1016/j.synthmet.2017.08.015.

(33) Kwak, K.; Cho, K.; Kim, S. Stable Bending Performance of Flexible Organic LightEmitting Diodes Using IZO Anodes. Sci. Rep. 2013, 3 (1), 2787. https://doi.org/10.1038/srep02787.

(34) Gioti, M.; Kokkinos, D.; Chaidou, C. I.; Laskarakis, A.; Andreopoulou, A. K.; Kallitsis, J. K.; Logothetidis, S. A Comprehensive Study of the Optical Properties of Emitting Polymers for Efficient Flexible OLED Devices. Phys. status solidi 2016, 213 (11), 2947-2953. https://doi.org/10.1002/pssa.201600651. 
(35) C, A.; Colella, M.; Griffin, J.; Kingsley, J.; Scarratt, N.; Luszczynska, B.; Ulanski, J. SlotDie Coating of Double Polymer Layers for the Fabrication of Organic Light Emitting Diodes. Micromachines 2019, 10 (1), 53. https://doi.org/10.3390/mi10010053.

(36) Céspedes-Guirao, F. J.; García-Santamaría, S.; Fernández-Lázaro, F.; Sastre-Santos, A.; Bolink, H. J. Efficient Electroluminescence from a Perylenediimide Fluorophore Obtained from a Simple Solution Processed OLED. J. Phys. D. Appl. Phys. 2009, 42 (10), 105106. https://doi.org/10.1088/0022-3727/42/10/105106. 


\title{
SUPPLEMENT MATERIALS
}

\section{Red Organic Light-Emitting-Diodes based on a N- Annulated Perylene Diimide Dimer}

\author{
Sergey V. Dayneko, ${ }^{a}$ Mohammad Rahmati, ${ }^{b}$ Majid Pahlevani, ${ }^{c}, *$ Gregory C. Welch ${ }^{a, *}$ \\ a Department of Chemistry, University of Calgary, 731Campus Place NW, Calgary, Alberta, \\ Canada T2N 1N4 \\ ${ }^{\mathrm{b}}$ Genoptic LED Inc, $600072^{\text {nd }}$ Ave SE, Calgary, AB, Canada, T2C 5B1 \\ 'Department of Electrical and Computer Engineering, Queen's University, 19 Union St., \\ Kingston, ON, Canada, K7L 3N6 \\ *E-mail: majid.pahlevani@ queensu.ca and gregory.welch@ucalgary.ca
}

TABLE OF CONTENTS

Materials and Methods

S2

Characteristics of OLEDs.

S4 


\section{Materials and Methods}

Materials: All chemicals/solvents were purchased from Millipore-Sigma and used without further purification. tPDI2N-EH was made as previously reported (Small Methods, 2018, 2, 180081). PFO and F8BT was purchased from Ossila.

UV-Visible Spectroscopy (UV-Vis): All optical absorption measurements were recorded using Agilent Technologies Cary $60 \mathrm{UV}$-Vis spectrometer at room temperature. Films were spin-cast onto Corning glass micro slides. Prior to use, glass slides were cleaned with soap and water, acetone and isopropanol, and followed by UV/ozone treatment using a Novascan UV/ozone cleaning system.

Atomic Force Microscopy (AFM): AFM measurements were performed by using a TT2- AFM (AFM Workshop) in tapping mode and WSxM software with a resonance frequency of $300 \mathrm{kHz}$, a force constant of $40 \mathrm{~N} / \mathrm{m}$ and a reflective back side aluminum coating (Tap300Al-G, BudgetSensors). Samples for AFM measurements were the same ones that were used to collect the respective device parameters.

OLED Device Fabrication and Testing (spin-coated): OLED devices were fabricated on ITOcoated glass substrates (sheet resistance of $10 \mathrm{Ohm} \mathrm{Sq}-1$ ), which were first cleaned by sequentially ultra-sonicating detergent and de-ionized water, acetone and isopropanol before use. ITO substrates were first pretreated under UV-ozone for 30 minutes. PEDOT:PSS were spin-coated onto the ITO-coated glass substrates at $3,000 \mathrm{rpm}$ for $60 \mathrm{~s}$ and annealed in air at $120^{\circ} \mathrm{C}$.

F8:F8BT: 
For deposition of the F8:F8BT active layer, the blend solution of F8:F8BT (ratio 19:1 at total concentration of $15 \mathrm{mg} \mathrm{mL}-1$ ) dissolved in toluene was spin-cast at 2,000 rpm on top of the PEDOT:PSS layer in air.

F8:tPDI2N-EH:

For deposition of the F8:tPDI2N-EH active layer, the blend solution of F8:tPDI2N-EH (different ratio at at total concentration of $15 \mathrm{mg} \mathrm{mL}-1$ ) dissolved in toluene was spin-cast on top of the PEDOT:PSS layer in air.

Finally, the $\mathrm{LiF}(1 \mathrm{~nm}) / \mathrm{Ag}(200 \mathrm{~nm})$ electrode was deposited using a thermal evaporation system through a shadow mask under a base pressure of $\sim 2 \times 10-6$ torr. The device area was $9 \mathrm{~mm} 2$ as defined by the overlapping area of the ITO films and top electrodes.

Current density-voltage (J-V) characteristics were measured using a Keithley 2612B sourcemeter combined with calibrated Si-photodiode and spectrometer. 


\section{Characteristics of OLEDs}
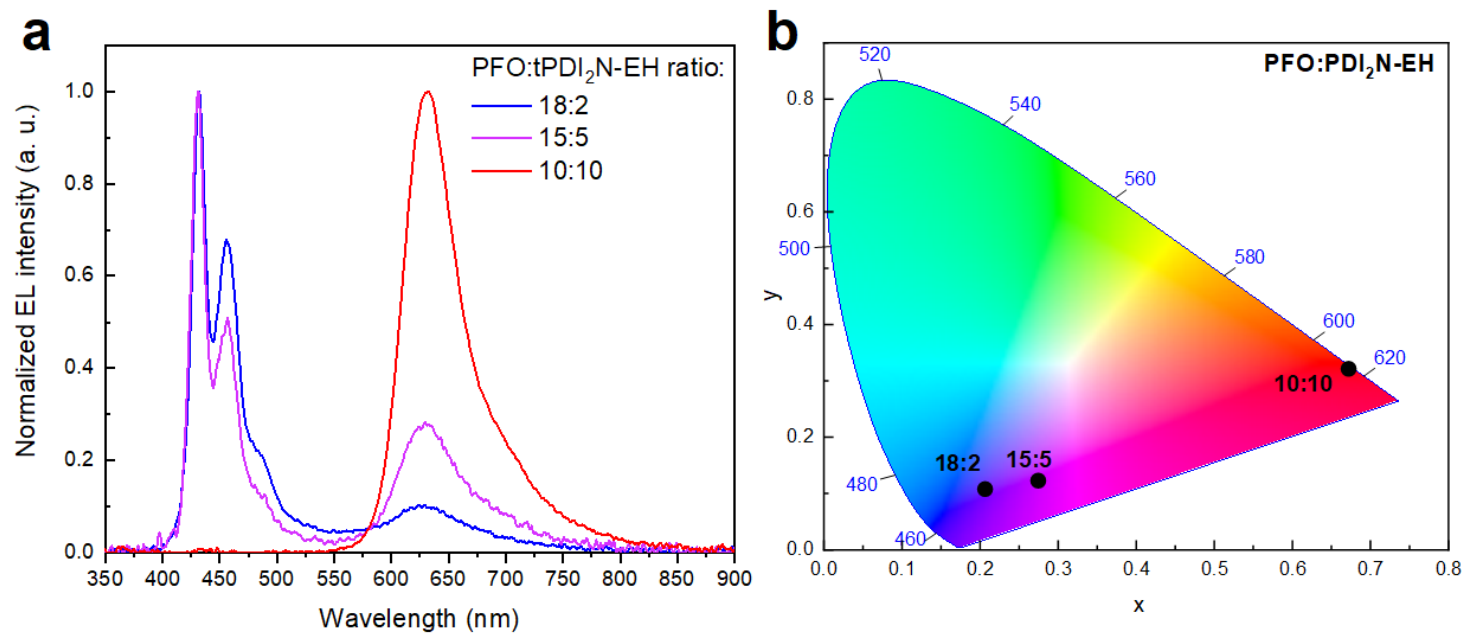

Figure S1. (a) Normalized electroluminescence (EL) and (b) color coordinates spectra of PFO:tPDI ${ }_{2} \mathrm{~N}-\mathrm{EH}-$ based OLEDs with different ratio of PFO and tPDI $\mathrm{N}-\mathrm{EH}$.

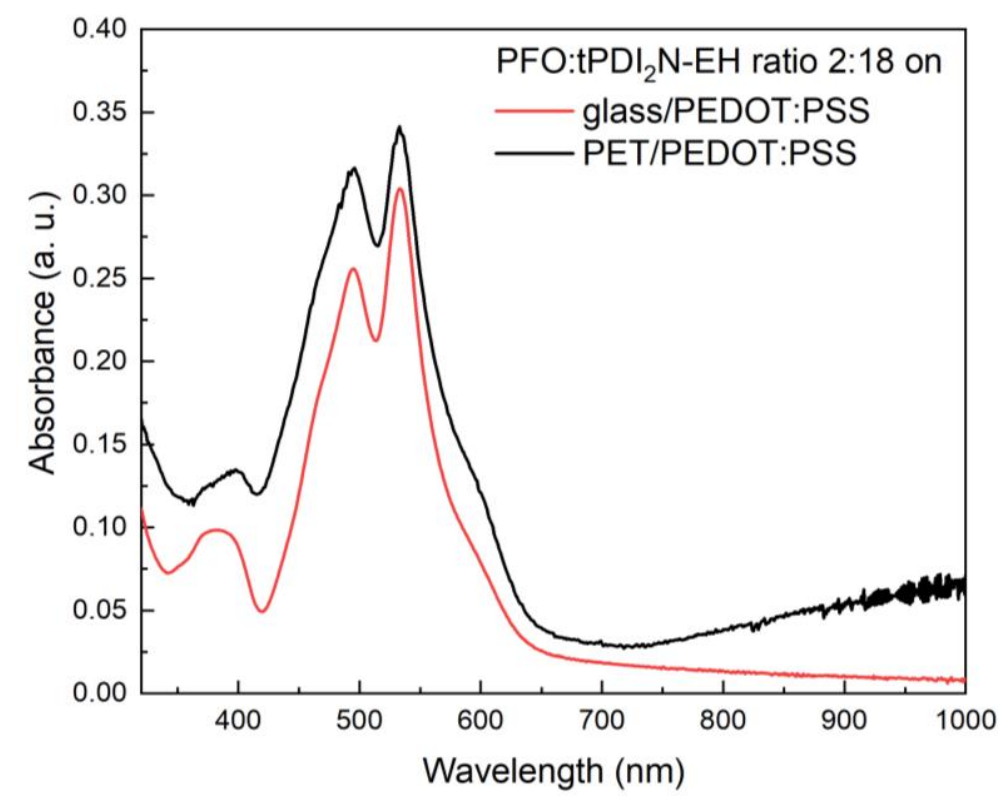

Figure S2. Optical absorption of OLEDs based on PFO:tPDI ${ }_{2} \mathrm{~N}-\mathrm{EH}$ with ratio of 2:18, spin-cast on glass/ITO/PEDOT:PSS and roll-to-roll coated on PET/ITO/PEDOT:PSS. 